\title{
Spatial Variability Analysis of Selected Soil Properties at Musayab, Babil, Iraq
}

\author{
Ahmad S. MuhaimeedAmal M. Saleh \\ Agriculture college/Baghdad University
}

\begin{abstract}
Great Musayab projectwas chosen to assess spatial variability of some soil properties, and furthermore, to investigate its implications for sampling design. Two hundred and forty composited soil samples werecollected acrossthe project and thesurrounding areas. Soil properties including electrolytic conductivity (ECe),calcium carbonate ( $\left.\mathrm{CaCO}_{3}\right)$, cation exchange capacity (CEC), as wellas sand, silt, and clay were analyzed for each sample. Classic statistical analysis showed that ECe had the highest CVwhichwas caused by some unusually high measurements. Semivariograms of allproperties were constructed, and compared to estimate thespatial variability of the soilproperties in the area. Thesemivariograms of soilproperties were best describedby aexponential model. Geo-statistical analysis showed that all the soil properties had a moderate or strong spatial dependency. Ordinary kriged maps indicated soils with high $\mathrm{ECe}, \mathrm{CEC}, \mathrm{CaCO}$, sand, silt, and clay in the surface horizons were found in the southern parts of the project. Water flows may be the dominant driving force for the spatial variability of chemical properties and texture parameters, implying more samples or analysis are required to achieve a similar level of precision.
\end{abstract}

\section{Introduction:}

Spatial dependence - the tendency for observations close together in space to be more highly correlated than those that are further apart.Also called spatial autocorrelation. Spatial dependence imputes that up to some distance apart from each other, two observations at different locations are not statistically independent (Chiles andDelfiner, 1999).

Semi-variance is a measure of the spatial dependence between two observations as a function of the distance between them. Semivariogram- a graph of how semivariance changes as the distance between observations changes.Semivariograms are used for measuring the degree of dissimilarity between observations as a function of distance. Based on the "first rule of geography" that things close together are more similar than things far apart, semi-variance is generally low when two locations are close to each other (i.e. observations at each point are likely to be similar to each other:. Typically, semi-variance increases as the distance between the locations grows until at some point the locations are considered independent of each other and semi-variance no longer increases (Karl and Maurer, 2010).

Geostatistics, as a rapidly evolving branch of applied statistics and mathematics that ofers a collection of tools, has been utilized extensively to illustrate the spatial variability of a variety of natural phenomena as well as spatial characteristics of soil attributes (Webster and Oliver, 2001; Hoover and WoIman, 2005; Jackson et al., 2007). Geostatistics takes into account both the structured and random characteristics of spatially distributed variables to provide optimal and unbiased estimations.This enables spatial relationships among sample values to be quantified and used for interpolation of values at unsampled locations (Zuo et al. 2008).

Huang et al. (2001) that knowledgeofsoilspatialvariabilityandrelationshipsamongsoilpropertiesisimportantfortheevaluationofagriculturalla ndmanagementpractices. Hisstudywastocharacterizethespatialvariationofselectedsoilpropertiesalongatransectacros safieldthatwaspartiallygrassedConservationReserveProgram

landfor 10years(CRP)andpartiallycontinuouslycroppedland(CCL).SoilchemicalpropertiesincludingpH,availableph osphorus(P),andsoiltotalcarboncontent(STC)werecomparedandgeostatisticallyanalyzedtoconstructsemivariograma ndestimateunsampledvalues. ThesemivariogramofSTCandpHexhibitedsphericalmodel.One-

dimensionalpHforCRPandCCLshowedseparatepatterns.SoilpHforCRPwashigherthanpHinCCL, concentrationofP wasobviouslyhigherintheCCLthaninCRP, andshowedincreasingstraightlinealongtransect.Soiltotalcarbonexhibiteda periodicbehavioralongtransectdependingmainlyon field topographic positionand less on landuse.

Iqbal et al. (2005) indicated that analysis and interpretation of spatial variability of soils is a keystone in site-specific farming. The objectives of his study were to determine thedegree of spatial variability of soil physical properties and variance structure, and to model the sampling interval of alluvial floodplain soils. Geostatistical analyses illustrated that the spatially dependent stochastic component was predominant over the nugget effect. Structured semivariogram functions of each variable were used in generating fine-scale kriged contour maps. The magnitude and spatial patterns soil physical property variability have implications for variable rate applications and design of soil sampling strategies in alluvial floodplain soils. 
Weindorf and Zhu(2010) explained that Non-agricultural lands are surveyed sparsely in general. Meanwhile, soils in these areas usually exhibit strong spatial variability which requires more samples for producing acceptable estimates. Semivariograms ofall properties were constructed, standardized, and compared to estimate the spatial variability of the soil properties in the area. Based on the similarity among standardized semivariograms, they found that the semivariograms could be generalized for physical and chemical properties, respectively. Optimal sampling density (OSD), which is derived from the generalized semivariogram and defines the relationship between sampling density and expected error percentage, was proposed to represent, interpret, and compare soil spatial variability and to provide guidance for sample scheme design. OSDs showed that chemical properties exhibit a stronger local spatial variability than soil texture parameters.

The purposes of this study was to describe and interpret the spatial distribution patterns of some soil properties in an area of Great Musayab, central of Iraq project based on geostatistics.

\section{Description of the study site:}

\section{Materials and Methods:}

The project is located within the lands ofthe governorate ofBabilbetweentheTigris andEuphratesriversontheleftbankoftheEuphrates River,justtenkilometersfromtheHindiyahdam and the boundaries ofthe project end about80kilometerseastofthe Euphrates river (Fig.1). The land sloping of the project rises towards the south $35 \mathrm{~m}$ abovesea level, and has a hot arid climate with subtropical influence. Summer temperatures frequently exceed $48{ }^{\circ} \mathrm{C}$. Winter temperatures infrequently exceed $21{ }^{\circ} \mathrm{C}$. Typically precipitation is low. Because of very high rates of evaporation, soil and plants rapidly lose the little moisture obtained from the rain, and vegetation could not survive without extensive irrigation. The land of the projectis naturally vegetated withAgool(Alhagimaurorum), but most of area is cultivated barley. The major soil families of the study area are (fine,Smectitic, superactive, calcareous, hyperthermic, VerticTorrifluvents) and (fine,Smectitic, active, calcareous, hyperthermic, TypicTorrifluvents) (Soil Survey Staf, 2010).

\section{Soil sampling and laboratory analysis}

Two hundred and forty soil samples were randomly selected,from0to $25 \mathrm{cmdepthfor} \mathrm{chemical} \mathrm{and}$ physicalpropertyanalyses. Soil properties including electrolytic conductivity $(\mathrm{ECe})$,calcium carbonate $\left(\mathrm{CaCO}_{3}\right)$, cation exchange capacity (CEC), as wellas sand, silt, and clay were analyzed for each sample by DepartmentofSoilInvestigationsLaboratory/Ministry of Irrigation (Muhammad et al., 2001).

\section{Statistical analysis}

Means, standard deviations, standard error, coefficients of variation(CV), skewness and kurtosis for each variable were analyzed using classical statistical methods. Data distributions were tested for normality.If data were not normally distributed, they were transformed using natural logarithmto a nearly normal distribution.

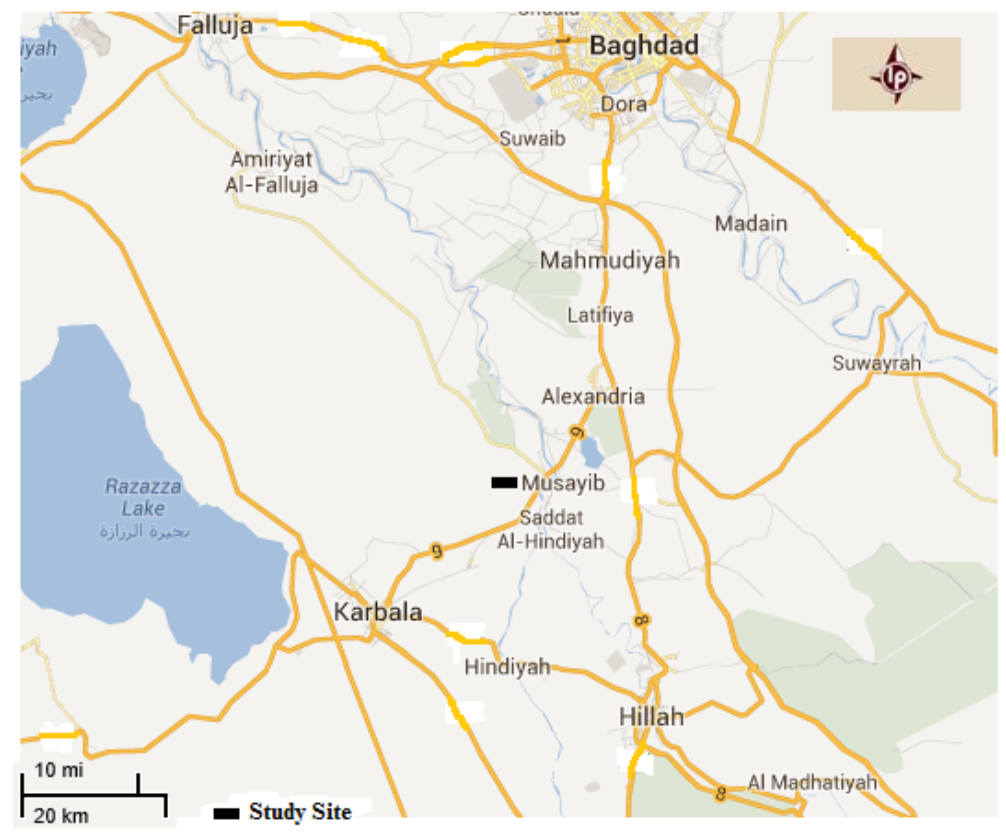

Figure1.Location of the study site at Musayab, Babil, Iraq. 


\section{Skewness and kurtosis Measurements}

Skewness is a measure of symmetry, or more precisely, the lack of symmetry. A distribution, or data set, is symmetric if it looks the same to the left and right of the center point.

Kurtosis is a measure of whether the data are peaked or flat relative to a normal distribution. That is, data sets with high kurtosis tend to have a distinct peak near the mean, decline rather rapidly, and have heavy tails. Data sets with low kurtosis tend to have a flat top near the mean rather than a sharp peak. A uniform distribution would be the extreme case.

\section{Definition of skewness}

For univariate data $Y_{1}, Y_{2}, \ldots, Y_{N}$, the formula for skewness is:

$$
\text { skewness }=\frac{\sum_{i=1}^{N}\left(Y_{i}-\bar{Y}\right)^{3}}{(N-1) s^{3}}
$$

Where:

$\bar{Y}$ is the mean;

Sis the standard deviation;

and $N$ is the number of data points.

The skewness for a normal distribution is zero, and any symmetric data should have a skewness near zero. Negative values for the skewness indicate data that are skewed left and positive values for the skewness indicate data that are skewed right(Hosking, 2006).

\section{Definition of Kurtosis}

For univariate data $Y_{1}, Y_{2}, \ldots, Y_{N}$, the formula for kurtosis is:

Where:

$$
\text { kurtosis }=\frac{\sum_{i=1}^{N}\left(Y_{i}-\bar{Y}\right)^{4}}{(N-1) s^{4}}
$$

$\bar{Y}$ is the mean;

$S$ is the standard deviation;

and $N$ is the number of data points.

The kurtosis for a standard normal distribution is three.In addition, positive kurtosis indicates a "peaked" distribution and negative kurtosis indicates a "flat" distribution (Hosking, 2006).

\section{Geostatistical Analyses}

Semivariance analysis using ArcGIS (v 9.3 - ESRIInc.) was used to quantify spatial autocorrelationbetween neighboringobservations, and to facilitate subsequent mapping of soil properties (Boerner et al, 1998). This analysis calculates an index of autocorrelation among groups of paired samples separated by increasing distances.

In order to interpolate surface maps of measured soil properties, the data was fitted to theoretical models. Data was fit to Exponential semivariogram models for the data that was ordinarykriged(Kriging is a geostatistical estimator that infers the value of a random field at an unobserved location) (Strano, 2008).

\section{Characteristics of the Semivariogram}

A number of parameters were extracted from the fitted models including the nugget (the semivariance at distance zero), the sill (the y-value at which the semivariance reaches an asymptote), and the range (the distance [x-value] at which this leveling occurs)(Fig.2). We used a system proposed by Cambardella et al. (1994) to define different classes of spatial dependence for the soil properties measured in this study that are based on the ratio of the nugget to the sill. If the nugget to sill ratio was $\leq 25 \%$, the soil property was considered to be strongly spatially dependent, or distributed in patches; if the ratio was between $26 \%$ and $75 \%$, the soil property was considered to be moderately spatially dependent; and if the ratio was $>75 \%$ the soil property was considered to be weakly spatially dependent (Cambardella et al. 1994). 


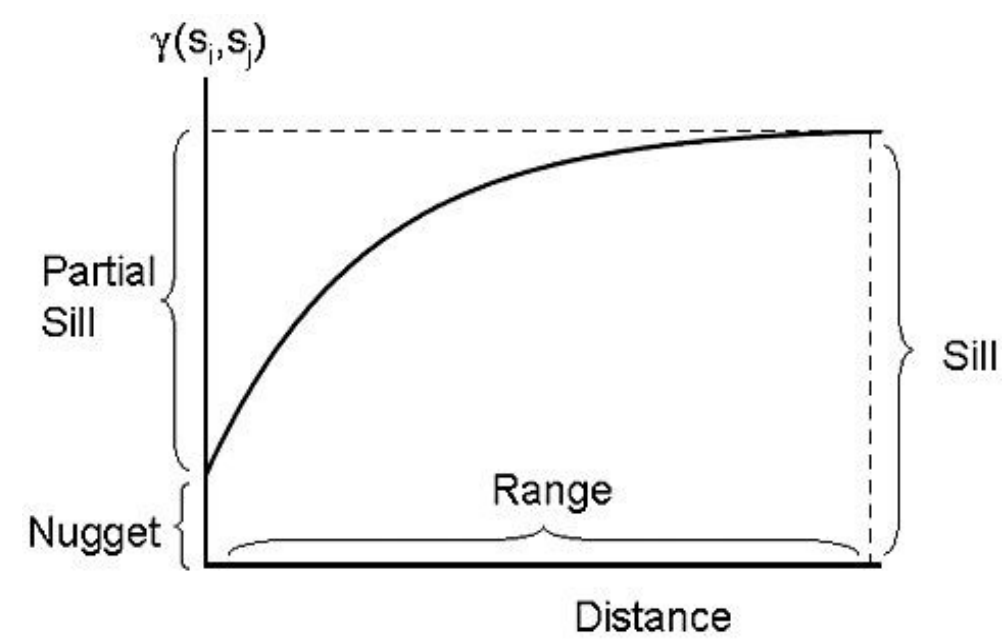

Figure 2.Characteristics of the Semivariogram.

\section{Semivariance}

The geostatistical measure of semivariance for interpolation of unsampled locations was determined using the general equation for semivariograms as presented below:

Where:

$$
\hat{\gamma}(h)=\frac{1}{2} \cdot \frac{1}{n(h)} \sum_{i=1}^{n(h)}\left(z\left(x_{i}+h\right)-z\left(x_{i}\right)\right)^{2}
$$

$\hat{\gamma}(h)_{\text {is the semivariance at lag distance } \mathrm{h} \text {; }}$

$n(h)$ is the number of observation pairs separated by h;

$z\left(x_{i}\right)$ is a measured variable atspatial location $i$;

$z\left(x_{i}+h\right)$ is a measured variable at spatial location $i+h$ (Bachmaier and Backes, 2008).

\section{Explanatory statistics}

\section{ResultsandDiscussion}

Descriptive statistics of measured soil propertieswere presented in Table 1.As the sampling scheme adopted in this study is almost evenly distributed, classic statisticscould be utilized to reveal the spatial variability of the soil properties.

Soil ECeranged from 1.10 to $210.00 \mathrm{dS} \mathrm{m}^{-1}$. Distribution of ECe was positively skewed, indicating that there were some extreme high values in this area ofGreat Musayab.ECehad the highestpositivekurtosis value indicating a "peaked" distribution. The $\mathrm{CV}$ is the ratio of the standard deviation(SD)to the mean values times 100.ECehad the highest CV(158.12)which was the only one over 100.The extremely high CV of ECein this study wascaused by some unusually high measurements. The reason for such high measurements may be geological,climatic trends, or human activities.

Cation exchange capacity (CEC)ranged from6.50 to $29.50 \mathrm{cmol}_{\mathrm{c}} \mathrm{kg}^{-1}$.Distribution ofCECwas negativelyskewed,indicating that there were someextreme low values of CECin this area. On the other handdistribution of CEC was kurtotic. Soil calcium carbonate $\left(\mathrm{CaCO}_{3}\right)$ ranged from194.00 to $340.00 \mathrm{~g} \mathrm{~kg}^{-1}$. Distribution ofCaCO $\mathrm{C}_{3}$ was negativelyskewed but was positivelykurtotic.

Descriptive statistics of soil texture parameters were: Sand varied from 1.00 to $85.00 \mathrm{~g} \mathrm{~kg}^{-1}$. Distribution of sand was positively skewed and also was kurtotic. Silt varied about 7 times from 11.00 to $70.00 \mathrm{~g} \mathrm{~kg}^{-1}$. Distribution of silt was negatively skewed but was positively kurtotic. Clay varied about 4 times from 4.00 to $46.00 \mathrm{~g} \mathrm{~kg}^{-1}$. Positive kurtosis values of clay and silt were similar.

Mean values of the soil properties except electrolytic conductivity (ECe) were similar with median values. This similarity was also noted by Emadi et al. (2008). Soil properties are often distributed normally in space.Only two of soil properties studied had a high skewness value greater than one (Table 1), implying that the frequency distributions were highly skewed. Special care should therefore be taken in applying the naturallogarithmic transformation to stabilize the variance (Grunwald et a1., 2007).

Correlation coefficients between the soil properties are given in Table 2. Correlations were found to be significantly high between all variables as generally reported, e.g., sand and silt $\left(\mathrm{r}^{2}=0.725^{* *}\right)$, sand and clay $\left(\mathrm{r}^{2}=\right.$ $\left.0.819^{* *}\right)$, silt and clay $\left(\mathrm{r}^{2}=0.946^{* *}\right)$. High significant correlations can also be identified between soil chemical properties, i.e., ECe and $\mathrm{CEC}\left(\mathrm{r}^{2}=0.788^{* *}\right), \mathrm{ECe}$ and $\mathrm{CaCO}_{3}\left(\mathrm{r}^{2}=0.708^{* *}\right), \mathrm{CEC}$ and $\mathrm{CaCO}_{3}\left(\mathrm{r}^{2}=0.960^{* *}\right)$. 
Spatial Variability Analysis of Selected Soil Properties at Musayab, Babil, Iraq

Table 1.DescriptivestatisticsofselectedsoilpropertiesatMusayab, Iraq.

\begin{tabular}{|c|c|c|c|c|c|c|c|c|c|c|}
\hline $\begin{array}{l}\text { Variabl } \\
\text { e }\end{array}$ & Mean & $\begin{array}{l}\text { Media } \\
\text { n }\end{array}$ & Min. & Max. & $\begin{array}{l}\text { Skewne } \\
\text { sscoef. }\end{array}$ & $\begin{array}{l}\text { Kurto } \\
\text { siscoef. }\end{array}$ & $\begin{array}{l}\text { Varian } \\
\text { ce }\end{array}$ & $\mathbf{S E} \mathbf{E}^{\text {a) }}$ & $\mathbf{S D}^{\mathrm{b})}$ & $C \mathbf{V}^{\mathfrak{c})}$ \\
\hline $\begin{array}{l}\text { ECedS } \\
\mathrm{m}^{-1}\end{array}$ & 24.967 & 5.200 & 1.100 & $\begin{array}{l}210.00 \\
0\end{array}$ & 2.890 & 12.935 & $\begin{array}{l}1558.51 \\
2\end{array}$ & 2.548 & $\begin{array}{l}39.47 \\
8\end{array}$ & 158.121 \\
\hline $\begin{array}{l}\text { CEC } \\
\text { cmol }_{\mathrm{c}} \mathrm{kg}^{-1}\end{array}$ & 19.088 & 18.600 & 6.500 & 29.500 & -0.226 & 4.124 & 16.483 & 0.262 & 4.060 & 21.270 \\
\hline $\begin{array}{l}\mathrm{CaCO}_{3} \mathrm{~g} \\
\mathrm{~kg}^{-1}\end{array}$ & $\begin{array}{l}280.75 \\
0\end{array}$ & $\begin{array}{l}279.00 \\
0\end{array}$ & $\begin{array}{l}194.00 \\
0\end{array}$ & $\begin{array}{l}340.00 \\
0\end{array}$ & -0.440 & 2.969 & $\begin{array}{l}1219.19 \\
7\end{array}$ & 2.254 & $\begin{array}{l}34.91 \\
7\end{array}$ & 12.437 \\
\hline $\begin{array}{l}\text { Sand } \mathrm{g} \\
\mathrm{kg}^{-1}\end{array}$ & 21.125 & 17.000 & 1.000 & 85.000 & 2.036 & 7.191 & 300.780 & 1.119 & $\begin{array}{l}17.34 \\
3\end{array}$ & 82.100 \\
\hline Silt $\mathrm{g} \mathrm{kg}^{-1}$ & 49.250 & 53.500 & 11.000 & 70.000 & -1.088 & 3.582 & 179.747 & 0.865 & $\begin{array}{l}13.40 \\
7\end{array}$ & 27.222 \\
\hline $\begin{array}{l}\text { Clay } \mathrm{g} \\
\mathrm{kg}^{-1}\end{array}$ & 29.625 & 30.000 & 4.000 & 46.000 & -0.635 & 3.853 & 83.229 & 0.588 & 9.123 & 30.795 \\
\hline
\end{tabular}

${ }^{\text {a) }}$ Standard error; ${ }^{\text {b) }}$ Standard deviation; ${ }^{\text {c) }}$ Coeficien ofvariation.

Table 2.Correlation coeficients between selected soil properties at Musayab, Iraq.

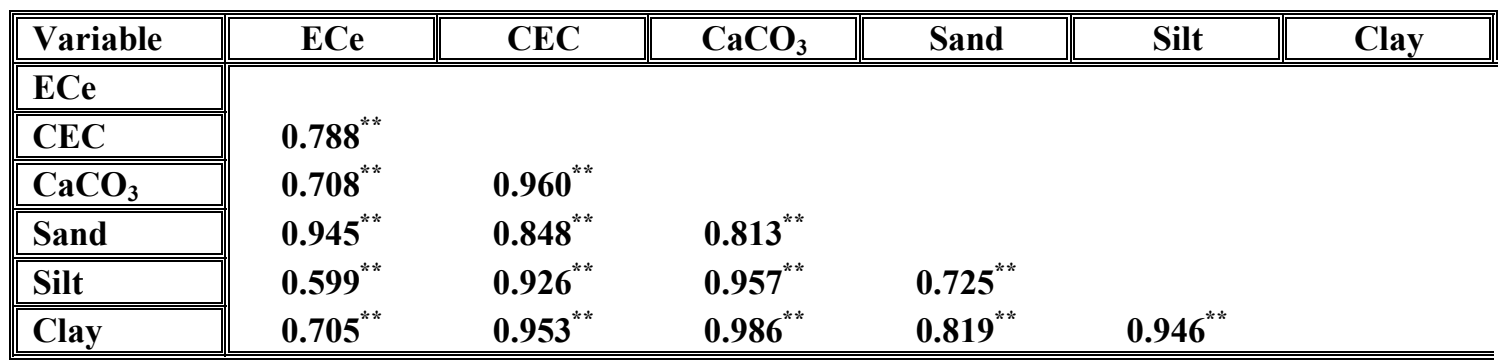

** Significant at $P=0.01$.

\section{Geostatistics}

The geostatistical parameters describing soil properties from adata set were listed in Table 3. Regression coefficients $\left(R^{2}\right)$ suggested that all models were best fitowing to the $R^{2}$ value (greater than 0.5 ) of the best-fitted model (Duffera et al., 2007).

Thesemivariogramsof soilproperties were best describedbyaexponential model (Fig. 3).Except soil texture parameter of sand, nuggets for all models were equal to zero.Smaller nugget indicates thesampling intervalis proper to reflect the variance. The sill value for soil ECe(917.982) was approximately twice as high thanthe sill value of soil $\mathrm{CaCO}_{3}$ (460.251), this implies that ECe had greater variation.

Table 3 shows thatall the soil properties have a moderate or strong spatial dependency (Cambardella et al. 1994). The effective ranges of $\mathrm{CEC}, \mathrm{CaCO}_{3}$, silt, and clay are greater than $2000 \mathrm{~m}$, indicating a large-patched distribution pattern (Fig. 4, 5). Given variables with similar nugget/sill ratios, related effective ranges may differ substantially.For instance, Soil ECe and siltin this study have similar ratios $(0.00)$ but they have effectiveranges of 1753.487 and2539.616 m, respectively.Apparently,ECe reached its maximumvariance level within a shorterlag distance,implying a stronger local variability than silt.

Thecross-validation value is thedetermination coefficient $\left(\mathrm{r}^{2}\right)$ of the correlation between the measured valuesand the cross-validation values, which were predicted based on thesemivariogram and neighbor values(Robertson, 2008).Despite strong spatial dependency forsoil ECe,the prediction efficiency $\left(\mathrm{r}^{2}\right)$ waslow, and for all the other variables the efficiency of spatial predictionranged from 0.346 to 0.640 .

Table 3.Semivariogram models and model parameters for selected soil properties atMusayab, Iraq.

\begin{tabular}{|c|c|c|c|c|c|c|c|c|c|}
\hline "Variable & (" Transf. $^{\text {a) }}$ & $\overline{\text { Model }^{\text {b) }}}$ & $\begin{array}{c}\text { Model } \\
R^{2}\end{array}$ & Nugget & "Sill & Nugget/Sill $^{\mathrm{c})}$ & $\begin{array}{c}\text { Spatial } \\
\text { dependency }^{\mathrm{d})}\end{array}$ & $\begin{array}{l}\text { Effective } \\
\text { Range }^{\mathrm{e})}\end{array}$ & $\begin{array}{c}\text { Cross } \\
\text { validation }\end{array}$ \\
\hline ECe & Yes & Exp & 0.589 & 0.000 & 917.982 & 0.000 & Strong & 1753.487 & 0.176 \\
\hline CEC & No & $\operatorname{Exp}$ & 0.500 & 0.000 & 6.712 & 0.000 & Strong & 2082.485 & 0.522 \\
\hline Silt & No & $\operatorname{Exp}$ & 0.500 & 0.000 & 69.912 & 0.000 & Strong & 2539.616 & 0.640 \\
\hline Clay & No & $\operatorname{Exp}$ & 0.611 & 0.000 & 42.320 & 0.000 & Strong & 2406.116 & 0.479 \\
\hline
\end{tabular}


a) Transformationoforiginalmeasurementsisappliedusingnaturallogarithm ifthecoefficientofskewnessisgreaterthanone; ${ }^{\text {b) }}$ Semivariogrammodel:

$\operatorname{Exp}(\operatorname{exponential}) ;{ }^{\mathrm{c})} \mathrm{Nugget} / \mathrm{sill}(\%)=($ nugget$/$ sill $) \times 100$;

Spatialdependencywasdefinedasstrong,moderate, weakorpurenuggetbas ed onnuggettosill ratios; ${ }^{\mathrm{e})}$ The effective range is the model range; ${ }^{\mathrm{f}}$ Thecrossvalidationvaluesforagivenvariablearecoefficientsofcorrelationbetweenobservedv alueandvaluescross-validatedbyGS + 9.3.
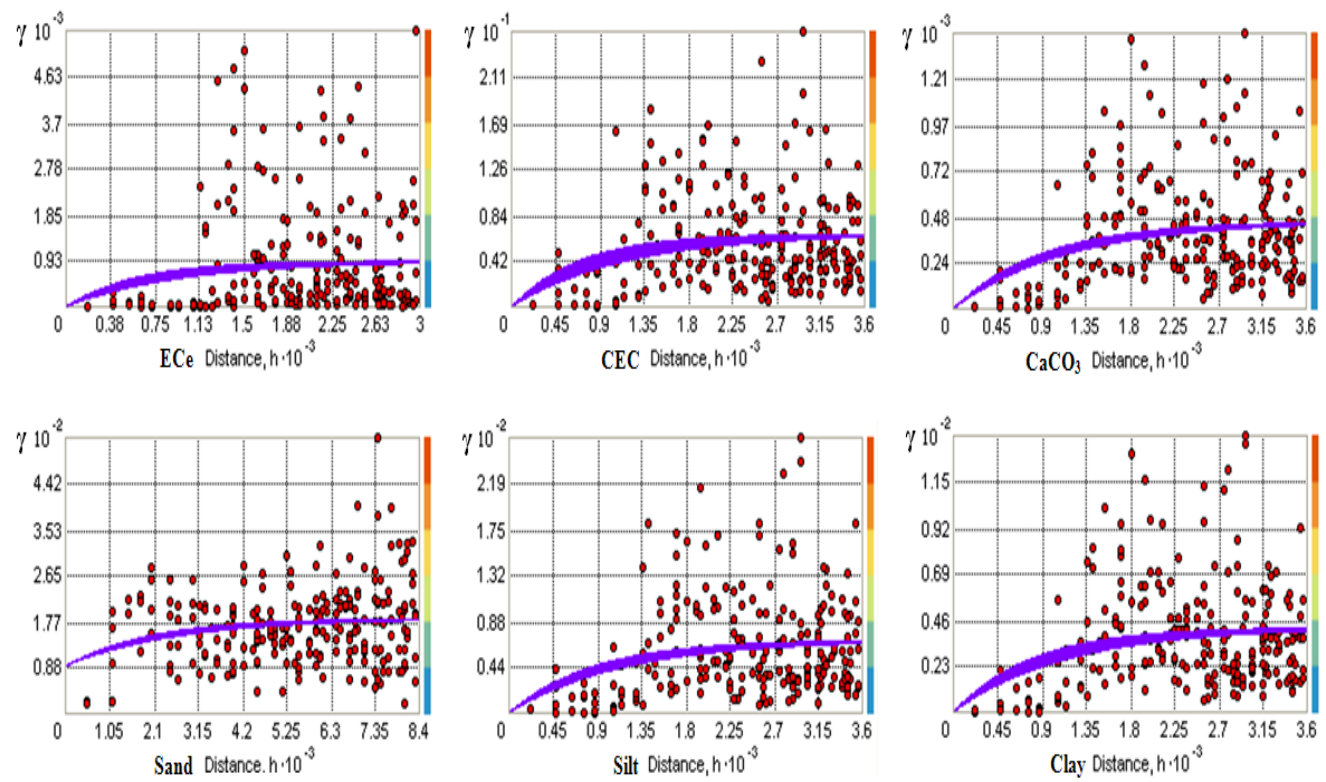

Figure 3.Generalizedsemivariogrammodelsforchemicalpropertiesand soiltexture parameters atMusayab, Iraq.
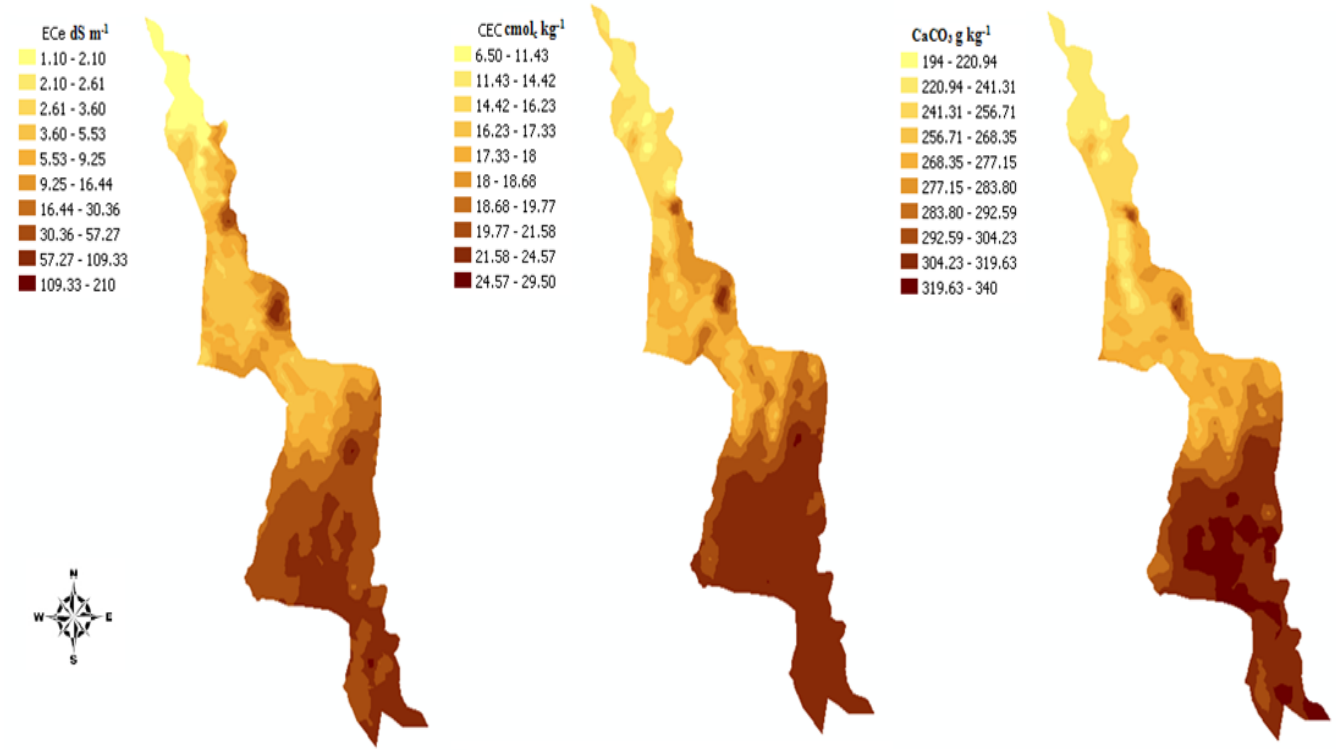

Figure 4.Interpolationmapsofselectedsoil $\mathrm{ch} \mathrm{e} \mathrm{m}$ i c a l properties usingordinarykriging atMusayab, Iraq. 

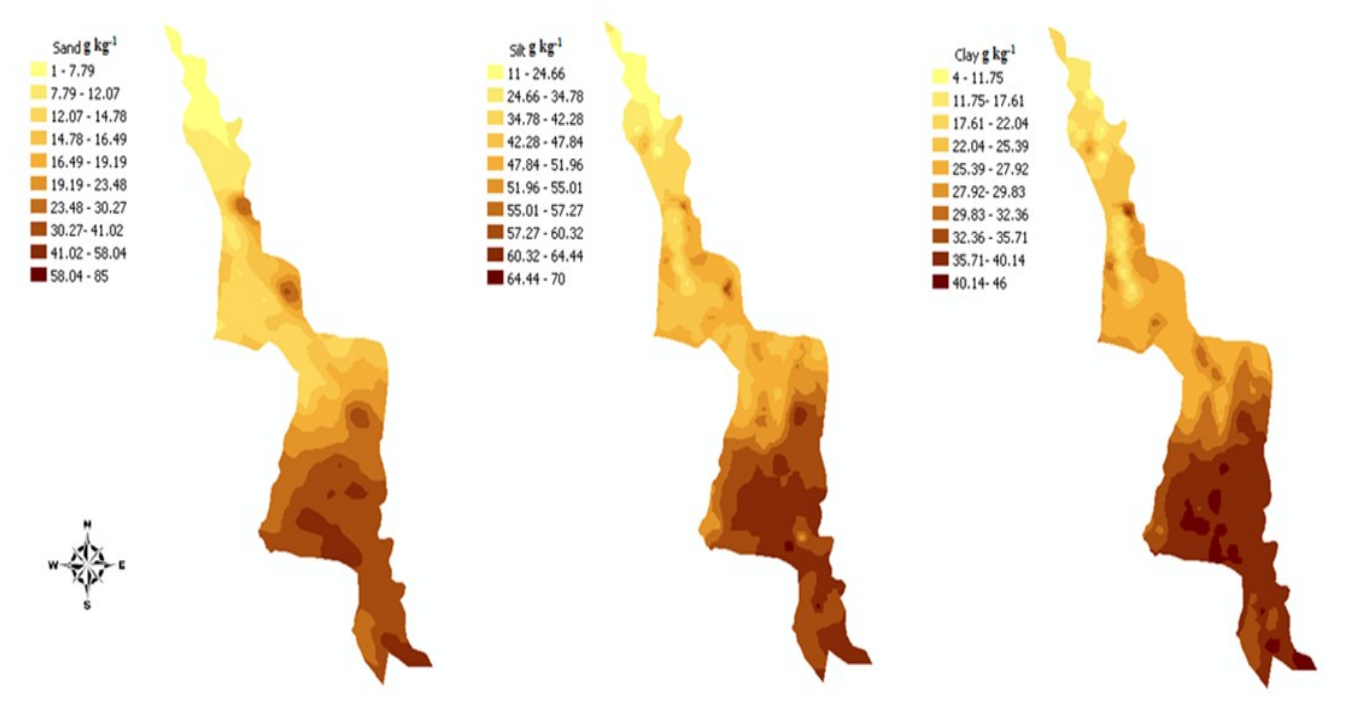

Figure 5.Interpolationmapsofsoiltexture parameters using ordinarykriging atMusayab, Iraq.

\section{Generalized semivariogram models}

General patterns can be identified forsoil chemical properties and soiltexture parameterswhich can be fitted byexponential models(Fig. 3). The soil propertiescorrelograms was reflected ina positive spatial autocorrelationstructure. The autocorrelation for soil texture parameter of sand at zero lag was 0.88 , and for all the other variables was 0.00 .It begins to increase as the lag distance increases, when the autocorrelation does not change significantlywith increasing lag distance, the plateau reached, called thesill, reflects the magnitude of random variation (Nielsen, 1998).

Soils in the Great Musayab project,especiallyalong the Tigris and Euphratesrivers,minimally developedEntisols showing little evidence ofpedogensis, therefore differences inspatial autocorrelation extent are notlikely related to pedogenic processes,such as eluviation andilluviation. These alluvial floodplainsoils have different stratificationextents for the soil properties, Thissuggests that the degree ofcumulization and the extent ofstratification during deposition of thealluvial materials is the most importantfactor in explaining the significantextent of spatial autocorrelation.

Ordinary kriged maps indicated soils with high $\mathrm{ECe}, \mathrm{CEC}, \mathrm{CaCO} 3$ in the surface horizons were found in the southern parts of the project (Fig. 4). Similarly, high sand, silt, and clay cotents were found in the same spatial pattern (Fig. 5).

The distinctness between the generalized semivariograms of chemical properties and texture parameters may be attributed to the different driving forces during soil formation. The waters of the Tigris and Euphrates are heavily siltladen, irrigation and fairly frequent flooding deposit large quantities of silty loam in much of the project area. Windborne silt contributes to the total deposit of sediments. By the time, the flow of the rivers is substantially reduced, and the surface area of the resulting sediment volume increases. The Tigris and Euphrates also carry large quantities of salts. These, too, are spread on the land by sometimes excessive irrigation and flooding. A high water table and poor surface and subsurface drainage tend to concentrate the salts near the surface of the soil. Most soils of Iraq are located in arid and semi-arid regions with high amount of calcium carbonate which results in higher calcification rate.Extensive leaching may have removed the $\mathrm{CaCO}_{3}$ from soil of the northern parts of the project area, but often the amount of $\mathrm{CaCO}_{3}$ in soils derived from calcareous parent material is considerable.

Water flows may be the dominant driving force for the spatial variability of texture parameters, soil particles can move with water and tend to deposit and accumulate on the areas where water flows slow down.

\section{Conclusions}

Classic statistical analysis showed that ECe had the highest CV which was the only one over 100. Mean values of the soil properties except electrolytic conductivity (ECe) were similar with median values. However, soil properties are often distributed normally in space.

Geo-statistical analysis showed that all the soil properties had a moderate or strong spatial dependency. General patterns can be identified for soil chemical properties and soil texture parameters which can be fitted by exponential models. Ordinary kriged maps indicated soils with high $\mathrm{ECe}, \mathrm{CEC}, \mathrm{CaCO}_{3}$ as well as sand, silt, and clay in the surface horizons were found in the southern parts of the project. Except soil texture parameter of 
sand, nuggets for all models were equal to zero. Smaller nugget indicates the sampling interval is proper to reflect the variance.

It should be noted that the generalized semivariogram models enables soil scientists to use measured soil chemical and physical data over greater distances to estimate attributes in the unsampled locations.

\section{References}

[1]. Bachmaier, M.; and M. Backes. 2008. "Variogram or Semivariogram - Explaining the Variances in a Variogram". Precision Agriculture, Springer-Verlag, Berlin, Heidelberg, New York.

[2]. Boerner, R. E. J.; A. J. Scherzer; and J. A. Brinkman. 1998. Spatial patterns of inorganic N, P availability, and organic C in relation to soil disturbance: a chronosequence analysis. Applied Soil Ecology, 7:159-177.

[3]. Cambardella, C. A.; T. B. Moorman; J. M. Novak; T. B. Parkin; D. L. Karlen; R. F. Turco; and A. E. Konopka. 1994. Fieldscale variability of soil properties in Central Iowa soils. Soil Sci. Soc. Am. J. 58: 1501-1511.

[4]. Chiles, J. P.; and P. Delfiner. 1999.Geostatistics, Modelling Spatial Uncertainty, Wiley-Interscience.

[5]. Duffera, M.; J. G. White; and R.Weisz. 2007. Spatial variability of Southeastern U.S. Coastal Plain soil physical properties: Implications for site-specific management.Geoderma.137: 327-339.

[6]. Emadi, M.; M.Baghernejad; and M.Maftoun.2008. Assessment of some soil in properties by spatial variability in saline and sodic soils in Arsanjan Plain, Southern Iran. Pakistan J. Biol. Sci. 11(2): 238-243.

[7]. Grunwald,S.;K. R. Reddy; J. P.Prenger; andM. M. Fisher.2007. Modeling of the spatial variability of biogeochemicalsoil properties in a freshwater ecosystem. Eco1. Mode1. 201: 521-535.

[8]. Hoover, K. A.; and M. G. Wolman. 2005. Beyond the semivariogram: Patterns, scale, and hydrology in a semi-arid landscape. Adv. Water Resour. 28: 885-898.

[9]. Hosking, J.R.M. 2006."On the characterization of distributions by their L-moments". Journal of Statistical Planning and Inference, 136: $193-198$.

$\begin{array}{lllll}\text { [10]. Huang, X.;E.L. } & \text { Skidmore; } & \text { G.Tibke. } & 2001 .\end{array}$ Selectedpapersfromthe10thInternationalSoilConservationOrganizationMeetingheldMay24-29,1999atPurdueUniversityandtheUSDAARSNationalSoilErosionResearchLaboratory. In:D.E.Stott,R.H.MohtarandG.C.Steinhardt(eds). PP. 641-647.

[11]. Iqbal, J.; J. A. Thomasson; J. N. Jenkins; P. R. Owens; and F. D. Whisler. 2005. Spatial variability analysis of soil physical properties of alluvial soils.Soil Sci. Soc. Am. J. 69: 1338-1350.

[12]. Jackson, R. D.; M. M. Bell; and C. Gratton. 2007. Assessing ecosystem variance at diferent scales to generalize about pasture management in southern Wisconsin. Agr.Ecosyst. Environ. 122: 471-478.

[13]. Karl, J.W.; and B.A. Maurer. 2010. Spatial dependency of predictions from image segmentation: a variogram-based method to determine appropriate scales for producing land-management information. Ecological Informatics. 5: 194-202.

[14]. Muhammad, I. J.; A.Khalaf; and F.Abd_AlSattar. 2001. Semi-detailed soil and hydrological investigation/governorates of Baghdad and Babil. DepartmentofSoilInvestigations; Soil and Water Resources Research Center; Ministry of Irrigation.

[15]. Nielsen, D.R. 1998. College on soil physics:Applied time series analysis and geostatistical methods.International Center for Theoretical Physics, Italy.

[16]. Robertson, G. P. 2008. GS+: Geostatistics for the Environmental Sciences. Gamma Design Software. Plainwell, Michigan, USA.

[17]. Soil Survey Staff. 2010. Keys to soil taxonomy. $11^{\text {th }}$.ed; 2010.USDA-Natural Resources Conservation Service.

[18]. Strano, M. 2008. "A technique for FEM optimization under reliability constraint of process variables in sheet metal forming". International Journal of Material Forming 1: 13-20.

[19]. Webster, R.; and M. A. Oliver. 2001.Geostatistics for Environmental Scientists. John W iley\& Sons, Chichester, UK.

[20]. Weindorf, D.C.; and Y. Zhu. 2010. Spatial Variability of Soil Properties at Capulin Volcano,New Mexico, USA: Implications for sampling strategy.Soil Science Society of China,20(2): 185-197.

[21]. Zuo, X.; H. Zhao; X. Zhao; T. Zhang; Y. Guo; S.Wang; and S. Drake. 2008. Spatial pattern and heterogeneity of soil properties in sand dunes under grazing and restoration in Horqin Sandy Land, Northern China. Soil Till. Res. 99: 202-212. 